\title{
AVALIAÇÃO DA EFICIÊNCIA DE INIBIDORES DE CORROSÃO ANÓDICOS E CATÓDICOS NA PROTEÇÃO DE BARRAS DE AÇO INSERIDAS EM ARGAMASSA POLIMÉRICA E GRAUTE CIMENTÍCIO
}

\author{
J.E.A. Bezerra ${ }^{1 *}$, A.E.B. Cabral ${ }^{2}$, O. Angel $^{3}$. \\ *Autor de Contacto: joseemidiobezerra@outlook.com \\ ${ }^{1}$ Universidade de Fortaleza, Centro de Ciências Técnológicas. Fortaleza, Brasil \\ ${ }^{2}$ Universidade Federal do Ceará. Fortaleza, Brasil. \\ ${ }^{3}$ Universidad Tecnologica Nacional. Córboba, Argentina
}

\begin{abstract}
RESUMO
Este artigo objetiva avaliar a eficiência se inibidores de corrosão em armaduras de concreto por análise comparativa de linhas de tendência dos potenciais de corrosão em duas barras de aço sem proteção, protegidas com nitritos ou zinco, inseridas em corpos de prova de concreto, argamassa polimérica e graute cimentício. Foram submetidos a ensaios induzidos com cloretos por ciclos de cinco dias de secagem em autoclave a $50{ }^{\circ} \mathrm{C}$ seguidos de umedecimento por imersão parcial em solução de 3,5\% de $\mathrm{NaCl}$ por dois dias. Os potenciais de corrosão foram medidos com voltimetro e semicélula de cobre/sulfato de cobre. Após 12 ciclos verificou-se que o melhor resultado foi alcançado com o aço protegido com nitrito inserido em graute cimentício.
\end{abstract}

Palavras chave: linha de tendência; potencial de corrosão; cloretos; graute; argamassa polimérica; inibidores de corrosão. 


\title{
RESUMEN
}

Este artículo tiene como objetivo evaluar la eficiencia de inhibidores de corrosión en armaduras de concreto mediante análisis comparativo de líneas de tendencia de potenciales de corrosión en dos barras de acero desprotegidas, protegidas con nitritos o zinc, insertadas en probetas de concreto, mortero polimérico y lechada cementosa. Fueron sometidos a pruebas inducidas con cloruros mediante ciclos de cinco dias de secado en autoclave a 50 ${ }^{\circ} \mathrm{C}$, seguido de humedecimiento por inmersión parcial en una solución de $\mathrm{NaCl}$ al 3,5\% durante dos días. Los potenciales de corrosión se midieron con un voltímetro y una media celda de cobre / sulfato de cobre. Luego de 12 ciclos se verificó que el mejor resultado se logró con el acero protegido con nitrito insertado en lechada cementosa.

\begin{abstract}
This article aims to evaluate the efficiency of corrosion inhibitors in concrete reinforcement by comparative analysis of trend lines of corrosion potentials in two unprotected steel bars, protected with nitrites or zinc, inserted in concrete specimens, polymeric mortar and cementitious grout. They were submitted to tests induced with chlorides by cycles of five days of drying in an autoclave at $50{ }^{\circ} \mathrm{C}$, followed by moistening by partial immersion in a 3.5\% $\mathrm{NaCl}$ solution for two days. Corrosion potentials were measured with a voltmeter and copper/copper sulphate half-cell. After 12 cycles, it was verified that the best result was achieved with the steel protected with nitrite inserted in cementitious grout.
\end{abstract}

Keywords: tendency line; corrosion potential; chlorides; grout; polymeric mortar; corrosion inhibitor.

\section{INTRODUÇÃO}

A partir de março de 2004, quando entrou em uso a NBR 6118:2003, passou-se a usar concreto com fator água/cimento e Fck adequados para a agressividade ambiental. Até então, usava-se concreto com Fck de $20 \mathrm{MPa}$ na construção de edifícios. Após vinte ou mais anos de uso, várias estruturas apresentaram fissuras estruturais provocadas pela expansão dos produtos da corrosão da armadura, e passaram a necessitar de reparos estruturais adequados. Para isto, são bastante usados os inibidores de corrosão comerciais à base de zinco que dão catódica ou à base de nitritos para a proteção anódica nas partes oxidadas da armadura. $\mathrm{O}$ recobrimento é geralmente feito com argamassas poliméricas ou graute cimentício. Os custos podem ser elevados e porisso, pesquisas sobre a eficiência dos inibidores de corrosão para o aço e dos materiais de reparos para o concreto são importantes, bem como para aumentar a durabilidade dos reparos.

A corrosão das armaduras do concreto é causada fundamentalmente pela carbonatação do concreto e pela interação com cloretos. A este respeito, Helene (2014) afirma que a perda da proteção natural da armadura proporcionada pelo cobrimento de concreto pode ocorrer por meio de diversos mecanismos sendo preponderantes a despassivação por carbonatação e por ação dos íons de cloro. Nas estruturas de concreto armado de edifícios e obras d'arte construídas nas áreas litorâneas, que estão submetidas ao aporte de névoas salinas 
transportadas pelo vento, os cloretos destroem a película passivante e juntamente com a água e oxigênio provocam a corrosão da armadura. CASCUDO (1997)

Battagin (2010) citado por Borges (2015) afirma que os agentes agressivos que atacam a pasta de cimento no concreto são os sais de magnésio e sulfatos, enquanto os cloretos são responsáveis pela corrosão das armaduras. Os cloretos, devido a suas dimensões muito pequenas tem grande mobilidade no interior do concreto podendo chegar facilmente às armaduras.

Giudice (2016) afirma que a corrosão eletroquímica é na verdade uma rede de pilhas galvânicas em curto circuito dispostas sobre a superfície do metal e, como explicado por Rüsch (1975) e citado por Helene (1976), este mecanismo requer a existência de condutor, eletrólito, diferença de potencial elétrico e oxigênio para ocorrer e se manter.

No interior do concreto, inicialmente o aço está protegido pelo óxido formado na sua superfície pela combinação com álcalis do cimento, mas pode ser alterado pela carbonatação do concreto e por ataque de cloretos e sulfatos.

Segundo Giǿrv (2014) "é bem conhecida a capacidade do concreto de proteger armaduras contra a corrosão, que se deve principalmente pela passivação eletroquímica das armaduras na solução alcalina presente nos poros do concreto, no entanto, a corrosão pode começar quando a passividade é rompida, parcial ou completamente, seja devido à carbonatação ou à presença de cloretos".

Este processo de corrosão do aço no concreto tem uma fase inicial, na qual os agentes agressivos modificam as condições do concreto no entorno da barra, despassivando-a e com isto permite a formação de uma célula de corrosão, responsável pela propagação da corrosão. Pazini e Meira, (2013), afirmam que os cloretos são os mais destruidores pela sua abundância nas áreas litorâneas onde localizam-se muitas estruturas de edifícios e por não se consumirem nas reações de oxirredução.

Porisso, é relevante estudar a eficácia dos materiais usados em reparos estruturais e, para isto, pode-se utilizar ensaios destrutivos e não destrutivos, tais como a medida da resistividade do material, dos potenciais de corrosão e da difusão de cloretos.

A resistividade, pode ser usada para estimar a probabilidade de corrosão e segundo o CEB 192/88 para o cimento Portland a $20^{\circ} \mathrm{C}$ as condições da Tabela 1 podem ocorrer.

Tabela 1 Resistividade x Risco de corrosão. Fonte: CEB 192/88

\begin{tabular}{|l|l|}
\hline Resistividadade $\mathrm{k} \Omega \mathrm{cm}$ & Probabilidade de corrosão \\
\hline$<100$ & Risco desprezível \\
\hline 50 a 100 & Risco baixo \\
\hline 10 a 50 & Risco moderado \\
\hline$<10$ & Risco alto \\
\hline
\end{tabular}

Da mesma forma, segundo Ribeiro e Cunha, (2018) a técnica da velocidade de pulso ultrassônico, permite obter informações sobre o módulo de elasticidade e a resistência à compressão, podendo identificar vazios no interior do material. A este respeito, Posetieri e Gioia (2017) esclarecem que o ultrassom é uma cria uma onda que supera os $20 \mathrm{KHz}$ e seria uma perturbação no meio em que se propaga, fazendo vibrar elasticamente as moléculas e átomos. Assim, a velocidade de pulso está relacionada com a qualidade do concreto e segundo a norma inglesa BS EM 1254-4/04, são admissíveis as seguintes condições (Tabela 2): 
Tabela 2. Velocidade de pulso ultrassônico e qualidade do concreto. Fonte: BS EM 1254$4 / 04$

\begin{tabular}{|l|l|}
\hline Velocidade de pulso ultrassônico $(\mathrm{m} / \mathrm{s})$ & Qualidade do concreto \\
\hline Maior do que $4.500 \mathrm{~m} / \mathrm{s}$ & Excelente \\
\hline Entre 4.500 e $3.500 \mathrm{~m} / \mathrm{s}$ & Bom \\
\hline Entre 3.500 e $3.000 \mathrm{~m} / \mathrm{s}$ & Duvidoso \\
\hline Entre 3.000 e $2.000 \mathrm{~m} / \mathrm{s}$ & Ruim \\
\hline Menor do que $2.000 \mathrm{~m} / \mathrm{s}$ & Muito ruim \\
\hline
\end{tabular}

O método de medição dos potenciais de corrosão mede a carga negativa provocada pelo movimento de elétrons liberados pelos íons ferrosos que se movem pelo eletrólito formado no concreto, fornecendo assim, informações sobre o estado de corrosão da armadura, de acordo com Zerbino e Carrasco (2012).

"É uma técnica bastante utilizada para medidas em laboratório e campo, devido à sua praticidade e por demandar por simples aparato para sua realização, além de ser uma técnica não destrutiva" (RIBEIRO e CUNHA, 2018).

A norma ASTM - C 876/91 estabelece os seguintes parâmetros para a possibilidade de corrosão em armaduras de concreto com base no potencial de corrosão medidos com semicélula de cobre/sulfato de cobre e que são apresentados na Tabela 3:

Tabela 3 Potencial x Probabilidade de corrosão. Fonte: ASTM - C 876/91

\begin{tabular}{|c|l|}
\hline $\begin{array}{l}\text { Potenciais de corrosão com semicélula de } \\
\mathrm{Cu} / \mathrm{SO}_{4} \mathrm{Cu}\end{array}$ & Probabilidade de corrosão \\
\hline Ecorr $<-200 \mathrm{mV}$ & Menos de $5 \%$ \\
\hline$-200 \mathrm{mV}<$ Ecorr $<-350 \mathrm{mV}$ & Cerca de $50 \%$ \\
\hline Ecorr $>-350$ & Mais de $95 \%$ \\
\hline
\end{tabular}

\section{OBJETIVO}

Este artigo tem como objetivo avaliar a eficiência dos inibidores de corrosão a base de zinco e a base de nitritos em barras de aço enseridas por argamassa polimérica e por graute cimentício em comparação com aquelas inseridas em concreto.

\section{PROGRAMA EXPERIMENTAL}

O programa experimental foi planejado para obter-se medições dos potenciais de corrosão nos corpos de prova prismáticos de argamassa polimérica, graute e de concreto com Fck = 24 MPa (NBR 9779/12) que servirá como base de referência. Todos os produtos são comercializados normalmente e de marcas diferentes.

Os corpos de prova foram submetidos a ensaios acelerados de corrosão por ação de cloretos ascudoe acompanhados por medições semanais da evolução dos potenciais corrosão, por 12 ciclos de secagem (5 dias no forno ${ }^{` a} 50^{\circ} \mathrm{C}$ ) e umedecimento em solução de $\mathrm{NaCL}$ a $3,5 \%$ (2 dias). 
Desta forma se induz a corrosão da armadura por ação de cloretos de forma acelerada como constatado por vários pesquisadores, Cabral (2000), Cascudo (1991); Monteiro (1996); Vasconcelos (1997).

\subsection{Caracterização dos materiais constituintes}

Os dados referentes aos materiais empregados para a elaboração do concreto usado nos corpos de provas são os seguintes:

Cimento Portland CP II F 32, composto com adição de filer calcário entre 6\% e 10\%. Blaine superior a $2.600 \mathrm{~cm} 2 / \mathrm{g}$, resistência à compressão $>32 \mathrm{MPa}$ aos 28 dias e atende à NBR $16697 / 18$.

Areia grossa proveniente do Rio Chorozinho, na localidade de Criancó no estado do Ceará, com granulometria mostrada no Gráfico 1:

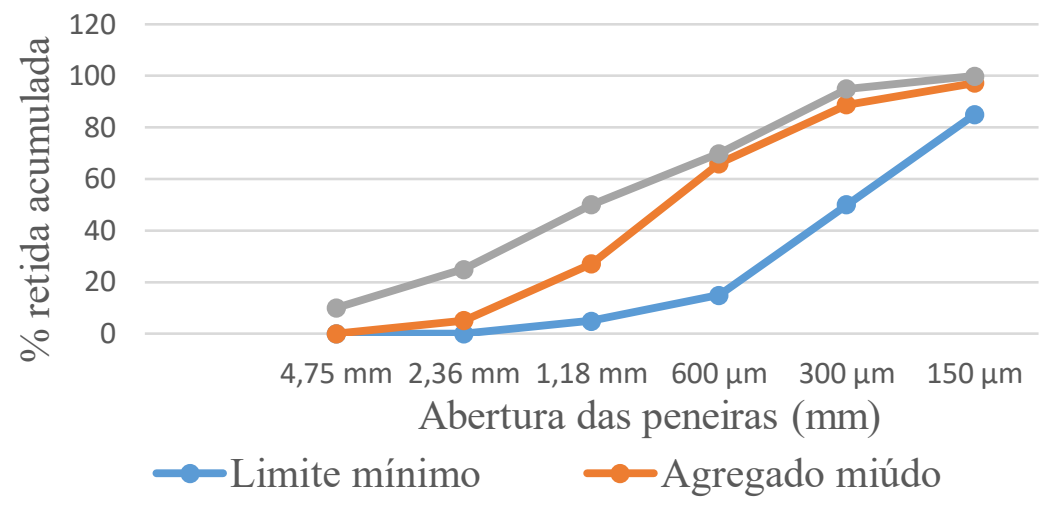

Gráfico 1: Análise granulométrica do agregado miúdo - NBR 7211/05. Autor (2019)

As propriedades desta areia estão expostas na Tabela 4.

Tabela 4. Propriedades físicas do agregado miúdo - NBR 7211/05. Fonte: O Autor (2019).

\begin{tabular}{|l|l|l|}
\hline Ensaio realizado & Resultado & Norma de ensaio \\
\hline Módulo de finura & 2,77 & NBR 7217/87 \\
\hline D máx. característica & $2,36 \mathrm{~mm}$ & NBR $7217 / 87$ \\
\hline Massa específica & $2,62 \mathrm{~g} / \mathrm{cm}^{3}$ & NBR $9776 / 87$ \\
\hline Massa unitária & $1,48 \mathrm{~g} / \mathrm{cm}^{3}$ & NBR $7251 / 82$ \\
\hline Teor de materiais pulverulentos & $2,0 \%$ & NBR $7219 / 87$ \\
\hline
\end{tabular}

A brita tem diâmetro máximo nominal 9,5 mm e módulo de finura, 5,94, oriunda de Pacatuba, município da Região Metropolitana de Fortaleza tem granulometria de acordo com Gráfico 2 . 


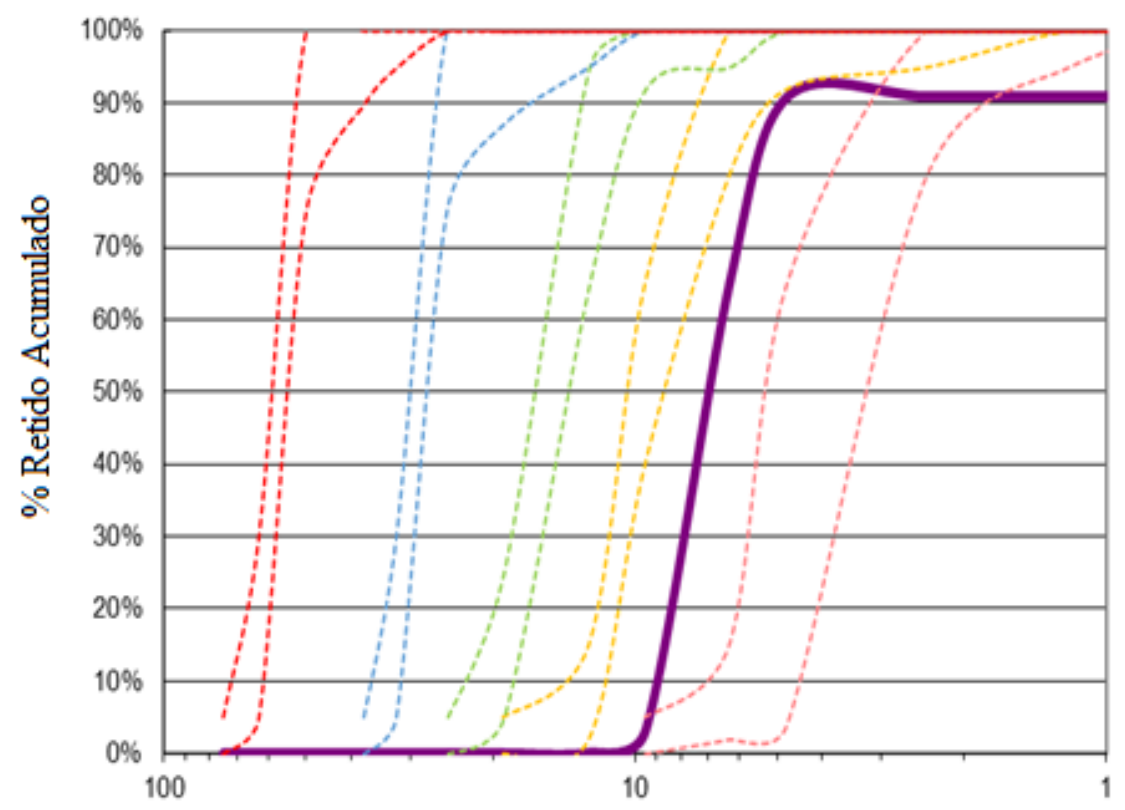

Abertura das peneiras ( $\mathrm{mm})$

Gráfico 2: Gráfico 2 Análise granulométrica do agregado graúdo - ABNT NBR ISO 33101. Fonte: Autor

- Concreto no traço 1:2:3 em peso com fator a/c de 0,6 e consumo de cimento de 344 $\mathrm{kg} / \mathrm{m}^{3}$, por ser o mais usado em estruturas com trinta anos de construção.

- Argamassa polimérica industrializada, cimentícia com agente adesivo acrílico, monocomponente de consistência tixotrópica.

- Graute industrializado, composto de cimento, agregados minerais e aditivo fluidificante, isento de cloretos e resistente à sulfatos.

- Aço CA 60 fabricado a partir do fio máquina (produto laminado a quente) com posterior processo de deformação a frio, como: trefilação ou laminação a frio. Tratase de um aço com baixo teor de carbono que apresenta microestrutura composta de Perlita e Ferrita encruados pelo processo de deformação a frio. (ABNT, NBR 7480:2007)

Com estes materiais foram moldados corpos cilíndricos de concreto e de argamassa estrutural segundo a NBR 7215/96 para os ensaios de caracterização da absorção por imersão (NBR 9778/05), absorção por capilaridade (NBR 9779/12), difusão de cloretos (ASTM 1202/04 e ASTM C 1556/04), ensaios mecânicos como a resistência à compressão (NBR 9779/12) e módulo de elasticidade para argamassa polimérica e graute obtendo os seguintes resultados: (Tabela 5).

Tabela 5 Características dos materiais. Fonte: Autor (2019).

\begin{tabular}{|l|c|l|l|}
\hline Ensaios / Material & Concreto & Argamassa & Graute \\
\hline & $1: 2: 3$ & Polimérica & Cimentício \\
\hline
\end{tabular}




\begin{tabular}{|l|l|l|l|}
\hline $\begin{array}{l}\text { Absorção de água por capilaridade (g/cm2). } \\
\text { S=19,64 }\end{array}$ & 0,47 & 0,26 & 0,31 \\
\hline Absorção de água por imersão. 72 hs. Ref (\%) & 7,96 & 6,68 & 8,13 \\
\hline Índice de vazios. 72 hs. Ref. (\%) & 20,8 & 6,28 & 17,54 \\
\hline $\begin{array}{l}\text { Massa específica da amostra seca. 72 hs. Ref (\%) } \\
\text { Massa específica da amostra saturada. 72 hs. Ref } \\
\text { (\%) }\end{array}$ & 2,16 & 2,53 & 2,16 \\
\hline
\end{tabular}

\subsection{Ensaio Acelerado de corrosão por indução de cloretos}

As barras de aço foram limpas com solução de ácido clorídrico 1:1 com 3,5\% de Hexametilanotetramina, conforme a ASTM G - 1/03. Posteriormente, um terço das barras foram pintadas com produto a base de zinco e outro terço foram pintadas com o produto a base de nitrito no comprimento de $5 \mathrm{~cm}$, deixando $4 \mathrm{~cm}$ sem pintura. As demais foram deixadas sem pintura. Os corpos de prova prismáticos têm as seguintes dimensões, mostrada na Figura 1.

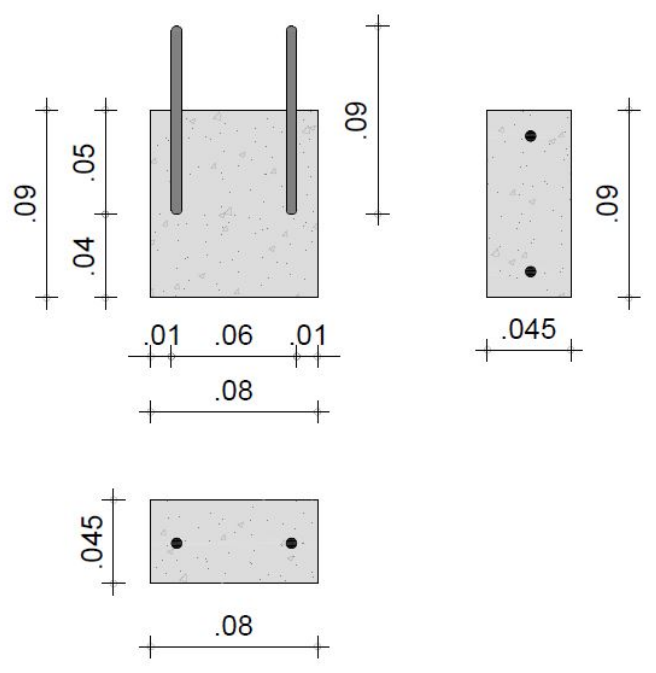

Figura 1 - Croquis do corpo de prova prismático (medidas em metro). Fonte: Autor (2019).

Após o período de cura úmida de cinco dias e 16 dias de cura ao ar, os corpos de provas foram pintados na base, no topo e nas laterais maiores, deixando as laterais menores ( $45 \times 80$ $\mathrm{mm}$ ) desprotegidas para ataque pela solução de $\mathrm{NaCL}$ a 3,5\%.

O ensaio teve início no $24^{\circ}$ dia da moldagem colocando-os por cinco dias na estufa na temperatura de $50^{\circ} \mathrm{C}$ e feita a medição do potencial de corrosão. Em seguida, foram colocados numa bandeja contendo a solução até a metade da altura das barras de aço por dois dias e novamente medidos os potenciais de corrosão. Este procedimento foi repetido doze vezes.

Os ensaios foram realizados no Laboratório de Materiais de Construção da Universidade de Fortaleza, no primeiro semestre de 2019.

Para a medição da velocidade de pulso foi usado um aparelho emissor/receptor de pulso ultrassônico seguindo o princípio do dispositivo de Werner. 
As resistências características à compressão foram obtidas através de ensaios de rompimento na prensa do Laboratório de Materiais de Compressão da Universidade de Fortaleza.

\section{RESULTADOS}

4.1 Resultados dos ensaios para caracterização dos materiais em relação à resistência à compressão, resistividade, velocidade de pulso ultrassônico e módulo de elasticidade e a indicação da quantidade de água em relação a cada material estão registrados na Tabela 6:

Tabela 6. Ensaio de Ultrassom. Fonte: Autor (2019).

\begin{tabular}{|c|c|c|c|c|c|c|c|c|}
\hline \multirow{2}{*}{ Material } & Fck & Resistividade & Pulso & Vp & Vs & $\begin{array}{c}\text { BS } \\
\text { EM }\end{array}$ & $\mathbf{E}$ & Relação \\
\cline { 2 - 9 } & $\mathbf{M P a}$ & $\mathrm{K} \Omega \cdot \mathrm{cm}$ & $\mu \mathrm{s}$ & $\mathrm{m} / \mathrm{s}$ & $\mathrm{m} / \mathrm{s}$ & $\begin{array}{c}\mathbf{1 2 4 4}- \\
\mathbf{4 / 4}\end{array}$ & $\mathbf{G P a}$ & água/x \\
\hline Concreto & 25 & 38,4 & 47,4 & 2191,00 & 2191,00 & Bom & 27,28 & 0,60 \\
\hline $\begin{array}{c}\text { Arg. } \\
\text { Polimérica }\end{array}$ & 33 & 20,1 & 51,0 & & & Bom & 36,92 & 0,15 \\
\hline Graute & 40 & 20,5 & 53,3 & 2616,00 & 2616,00 & Bom & 28,93 & 0,17 \\
\hline
\end{tabular}

\subsection{Potenciais de corrosão}

Estabelecidos as características dos materiais utilizados, pode-se avaliar a eficiência dos revestimentos inibidores de corrosão e dos materiais quando submetidos ao ataque de cloretos. O método escolhido foi indicado por oferecer resultados com boa precisão em períodos curtos. Assim, após doze ciclos foram obtidos os dados referentes a evolução dos potenciais de corrosão nos corpos de prova prismáticos de concreto, de argamassa polimérica e de graute, com barras de aço CA-60. As evoluções dos potenciais de corrosão são apresentadas nos gráficos a seguir. Os resultados para os ferros sem proteção estão no Gráfico 3. 


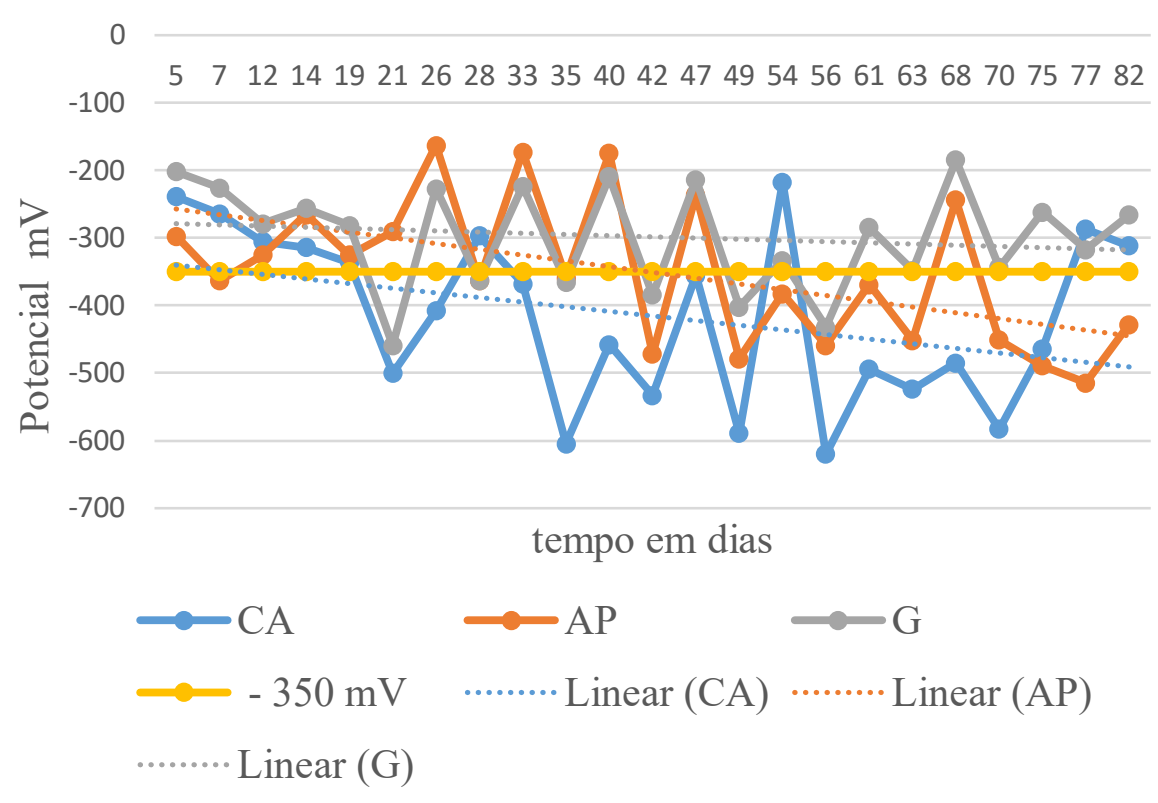

Gráfico 3: Linha de tendência dos potenciais de corrosão, para as barras de aço ao natural, sem pintura de proteção. Fonte: Autor (2020).

Os resultados dos ensaios feitos com as barras com proteção anódica tiveram o seguinte comportamento:

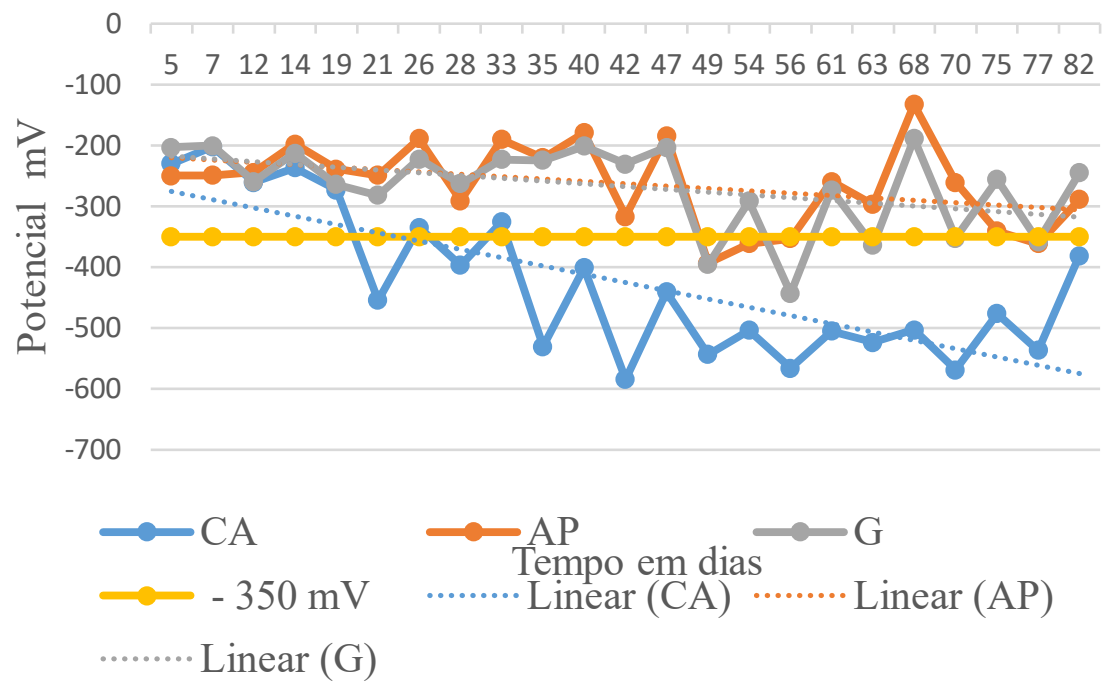

Gráfico 4: Linha de tendência dos potenciais de corrosão, para as barras de aço protegidas com pintura à base de nitritos. Fonte: Autor (2020).

Os resultados dos ensaios feitos com as barras com proteção catódica são expostos no Gráfico 5: 


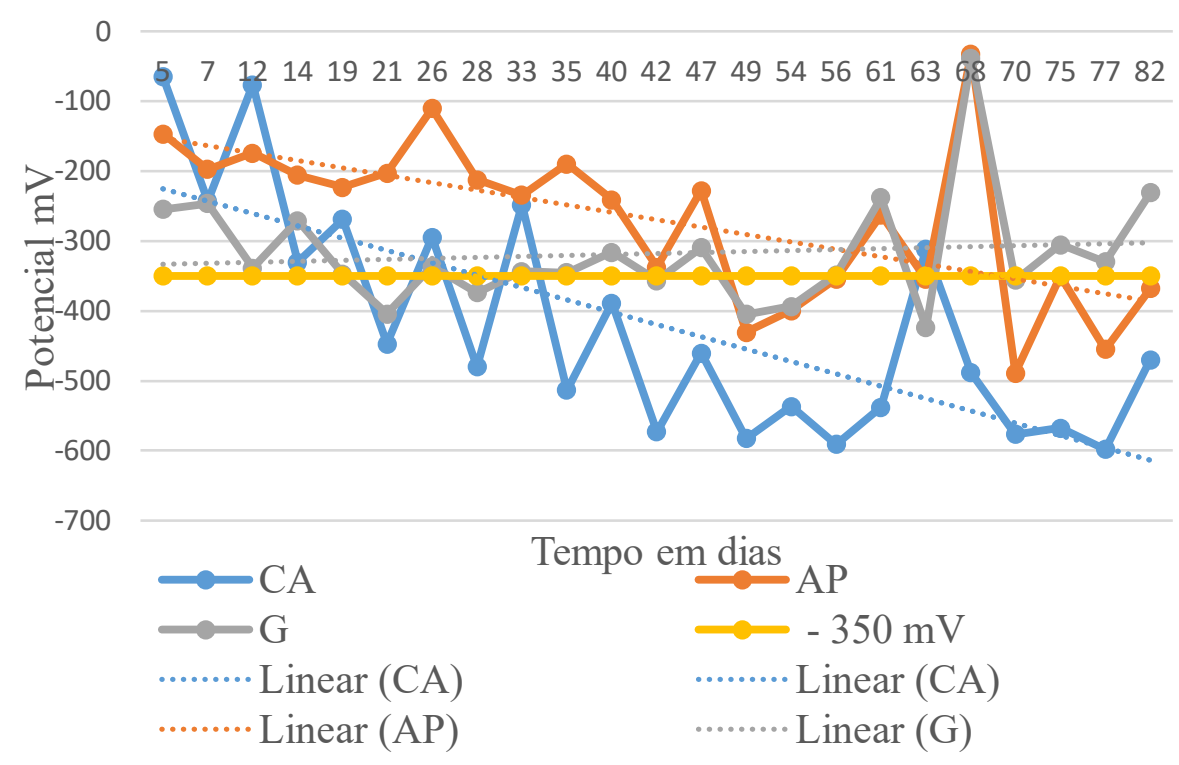

Gráfico 5: Linha de tendência dos potenciais de corrosão, para as barras de aço protegidas com pintura à base de zinco. Fonte: Autor (2020).

Com base nas linhas de tendência para que o potencial de corrosão atinja o valor de $-350 \mathrm{mV}$ quando a probabilidade de estar havendo corrosão nas barras de aço é de $95 \%$ foi elaborada a Tabela 7.

Tabela 7: Tempo (em dias) para atingir - 350 mV. Fonte: O Autor (2020).

\begin{tabular}{|c|c|c|c|}
\hline \multirow{2}{*}{ Material } & \multicolumn{3}{|c|}{ Tipo de proteção nas barras de aço } \\
\cline { 2 - 4 } & Sem proteção & Inibidor: Nitrito & Inibidor: Zinco \\
\hline Concreto & 7 dias & 21 & 28 \\
\hline Argamassa Polimérica & 42 dias & Não atingiu & 68 \\
\hline Graute & Não atingiu & Não atingiu & Não atingiu \\
\hline
\end{tabular}

\section{CONCLUSÕES}

Os ensaios de caracterização dos materiais indicaram que todos os materiais empregados nesta pesquisa são adequados para reparos estruturais em concreto armado, porém, o ensaio de indução de corrosão por ataque de cloretos demonstrou que as barras de aço protegidas por revestimentos a base de nitritos e recobertas com graute cimentício obtiveram os melhores resultados, embora a proteção a base de zinco e o recobrimento com argamassa polimérica também apresentem bons desempenhos.

Recomenda-se que sejam feitas novas pesquisas com uma maior abrangência de marcas e fabricantes, inclusive com corpos de prova submetidos à principal causa de corrosão no concreto armado que é a carbonatação e em reparos parciais, onde as barras de aço ficam em contato com o concreto original e com os inibidores de corrosão. 
Deve-se salientar que, atualmente, por força da Norma NBR 6118:14, são usados concretos mais resistentes na construção das estruturas, porém, esta classe de resistência para o concreto, entre 20 a $25 \mathrm{MPa}$ foi bastante usada há cerca de trinta anos e são as estruturas que atualmente estão apresentando mais ocorrências de fissuração por corrosão da armadura.

\section{REFERÊNCIAS}

Associação Brasileira de Normas Técnicas. (2014). NBR 6118: Projeto de estruturas de concreto armado - Procedimento. Rio de Janeiro.

Associação Brasileira de Normas Técnicas. (2012). NBR 9204: Concreto endurecido Determinação da resistividade elétrica volumétrica - Método de ensaio, 12 p. Rio de Janeiro Associação Brasileira de Normas Técnicas. (1984). NBR 8522: Módulo de elasticidade. Rio de Janeiro.

Associação Brasileira de Normas Técnicas. (2015). NBR 5738: Concreto - Procedimento para moldagem e cura de corpos de prova. Rio de Janeiro, $9 \mathrm{p}$.

Associação Brasileira de Normas Técnicas. (2007). NBR 5739: Concreto - Ensaio de compressão de corpos de prova cilíndricos. Rio de Janeiro. 9 p.

Associação Brasileira de Normas Técnicas. (2005). NBR 7211. Agregados para concreto Especificação. Rio de Janeiro.

Associação Brasileira de Normas Técnicas. (1991): NBR 11578: Cimento Portland Composto. Rio de Janeiro.

Associação Brasileira de Normas Técnicas. (2013). NBR 8802: Concreto endurecido Determinação da velocidade de propagação de onda ultrassônica. Rio de Janeiro, 8p.

Associação Brasileira de Normas Técnicas. (1993). NBR 95739: Migração por cloretos, ensaios mecânicos como a resistência à compressão. Rio de Janeiro.

Associação Brasileira de Normas Técnicas. (2005). NBR 9778: Argamassa e concreto endurecidos - Determinação da absorção de água, índice de vazios e massa específica. Rio de Janeiro. 4 p.

Associação Brasileira de Normas Técnicas. (2018). NBR 7480: Aço destinado a armaduras para estruturas de concreto armado - Especificação. São Paulo: ABNT.

American Society For Test Materials. (1991): ASTM - C 876. Standard Test Method for Corrosion Potentials of Uncoated Reinforcing Steel in Concrete corrosion potential.

American Society For Test Materials. (2003). ASTM - G1: Preparing, cleaning and evaluating corrosion test especimens.

BASF. "Manual Técnico". (2017): https://assets.master-builders-solutions.basf.com/pt-br. Acesso 29/05/2019.

Borges, 1. F. (2015: "Deterioração química e biológica do concreto". Dissertação de mestrado. Uberlância: UFU.

British Standards. EN 12504-4 (2000): Testing Concrete. Determination of ultrasonic pulse velocity. London.

Cascudo, Osvaldo. (1997): “O controle da corrosão das armaduras de concreto. Inspeção e técnicas eletroquímicas". São Paulo: Pini.

Cimento.org. (2019). "CP II F-Cimento Portland composto com Fíler". Acesso 29/05/2019.https://cimento.org/cp-ii-f-32-cimento-portland-composto-com-filer/

Giudice. Carlos. (2016). "Corrosión Metálica y mecanismo de protección de los pigmentos inhibidores em pinturas". Notas de aulas. Fortaleza: UFC. 
Gjov. Odd E. (2014). "Durability and design of concrete structures in several enviroments". Oslo: CRC Press. 2 ed.

Helene, P.R.L. (2014). "A Nova NB 1/2003 (NBR 6118) e a vida útil das estruturas de concreto armado". https://www.phd.eng.br/wp-content/uploads/2014/06/185.pdf

Helene, P.R.L. (1976). “Corrosão em armaduras para concreto armado” São Paulo: Pini. Pacheco, J.; Bilesky, P.; Morais, T.R.; Grando, F.; Helene, P.R. L. (2014). "Considerações sobre o Módulo de Elasticidade do Concreto". 56 IBRACON. ISSN 2175-8182. Natal: IBRACON.

Pazini. E.F.; Meira, G.R. (2013). "Corrosión de armaduras en estructuras de hormigón". Boletín no 6. Mérida: Alconpat Internacional.

Posetiere. M.J., Gioia, C. (2017). “Tecnología del Hormigón. Guia de Ensayos". Córdoba: Educo.

Proceq S.A. (2015). Canin. "Corrosion Analyzing Instrument. Operating instructions". Suitzerland. Schwerzenbach.

Proceq S.A. (2015). "Pundit PL 200. Shear Wave Transducers $250 \mathrm{kHz}$. Operating Instructions". Suitzerland. Schwerzenbach.

Proceq S.A. (2015). "Resipod Operating Instrutions". Suitzerland. Schwerzenbach.

Ribeiro, D. V. e Cunha; M. P. T. (2018). "Técnicas de avaliação e monitoramento da corrosão em estruturas de concreto armado. Corrosão e degradação em estruturas de concreto armado: teoria, controle e técnicas de análise e intervenção". Rio de Janeiro: Elsevier.

Vedacit.(2019).“Manual Técnico, 48ª Edição”.

http://www.vedacit.com.br/uploads/biblioteca/manual-tecnico-vedacit-5.pdf.

Zerbino, R. L.; Carrasco, M.F. (2012). "Hormigón endurecido. Ese material llamado hormigón". Buenos Aires: Asociación Argentina de Tecnología del Hormigón. 